\title{
Dicrocoeliosis of Old Mouflon Ewes - Effect on Biotransformation Enzymes and Metabolism of Anthelmintics In Vitro
}

\author{
Veronika Kř́žová, Jiří Lamka, Barbora Szotáková, Ivan Vokřál, Veronika Srpová, \\ Marie Urbánková, Vladimír Kubíček, Milan Nobilis and Lenka Skálová*
}

\begin{abstract}
Charles University in Prague, Faculty of Pharmacy in Hradec Králové, Heyrovského 1203, Hradec Králové, Czech Republic
\end{abstract}

\begin{abstract}
Parasitic infections can modify the host's ability to metabolize drugs by altering the biotransformation enzymes. Mouflon (Ovis musimon), the wild sheep, is very sensitive to parasitic diseases. In the present study, in vitro activities of thirteen hepatic biotransformation enzymes and the in vitro metabolism of albendazole and flubendazole were compared in old mouflon ewes, either non-infected or infected with lancet flukes (Dicrocoelium dendriticum). The most pronounced decline in 6 $\beta$-testosteron hydroxylase, glutathione-S-transferase and UDP-glucuronosyl transferase activities was observed in Dicrocoelium-infected animals. In addition, dicrocoeliosis caused a decrease in both albendazole and flubendazole phase I hepatic metabolism. However, the changes were very slight therefore any undesirable alterations in albendazole and flubendazole pharmacokinetics are not expected. Decreased activities of $6 \beta$-testosterone hydroxylase, glutathione-S-transferase and UDP-glucuronosyl transferase can impair drug elimination from the infected animals. This should be taken into consideration in pharmacotherapy or pharmacoprophylaxis of mouflons and sheep.
\end{abstract}

Keywords: Dicrocoelium dendriticum, lancet fluke, albendazole, flubendazole, drug metabolism.

\section{INTRODUCTION}

Mouflon (Ovis musimon) represents a popularly hunted and food-producing animal species in Central Europe. In the Czech Republic, the mouflon population is comparable to that of domestic sheep (Ovis aries). Mouflon is very sensitive to many parasitic diseases (muelleriosis, trichostrongylosis, fasciolosis or dicrocoeliosis). These diseases cause health problems, untimely death of animals and last but not least economic losses for breeders. Therefore anthelmintics are used frequently in the breeding of mouflon, especially in game-parks and farms.

Dicrocoeliosis belongs among most important and frequent pasture helminthoses in sheep [1] and mouflons. It is caused by Dicrocoelium spp. (Platyhelminthes, Trematoda, Dicrocoeliidae), commonly known as "lancet fluke" or "small liver fluke".

Despite its widespread distribution (Europe, Asia, North Africa and North America), dicrocoeliosis is not very well examined and is often underestimated by researchers and practitioners in many countries. This is because of the multiple parasitic infections and the difficulties encountered in diagnosing it [2]. The diagnosis of dicrocoeliosis is still based mainly on the detection of the eggs in the host feces [3] and on the postmortem examination of liver and bile [4]. Immunodiagnostic methods [5] are useful too.

Control of the small liver flukes infection comprises restrictive husbandry practices and treatment of hosts. Methods directly affecting the intermediate host populations are not

*Address correspondence to this author at the Department of Biochemical Sciences, Faculty of Pharmacy, Charles University, Heyrovského 1203, Hradec Králové, CZ-500 05, Czech Republic; Tel: +420 495067322; Fax: +420 495067168; E-mail: lenka.skalova@faf.cuni.cz feasible because of the high cost and ecological reason. Correct treatment (in terms of timing and dosage) plays a fundamental role in anthelmintic resistance development. The strategic treatment of all animals exposed to infection by free grazing is the most common option for dicrocoeliosis control [6]. Several benzimidazoles, probenzimidazoles, praziquantel, closantel, oxyclosanid and diamphenetid have been verified for treatment of dicrocoeliosis [7].

Albendazole (ABZ; methyl-[5-(propylsulphanyl)-1H-benzimidazole-2-yl]-carbamate) is a benzimidazole anthelmintic with broad-spectrum activity. In domestic sheep [8] or mouflon [9], ABZ is rapidly metabolized through a two-step Soxidation. In the first step, chiral albendazole sulfoxide (ABZSO) is formed, which is further oxidized to albendazole sulfone $\left(\mathrm{ABZSO}_{2}\right)$. The structure of $\mathrm{ABZ}$ and its main metabolites are shown in [10]. While ABZSO is responsible for the anthelmintic activity, $\mathrm{ABZSO}_{2}$ is pharmacologically inactive [11]. Successful treatment of dicrocoeliosis in domestic sheep requires a repeated administration of therapeutics [12] or a higher single dose of ABZ [13]. In both ways, the total therapeutic dosage exceeds the dosage commonly used in other more common helminthoses.

Flubendazole (FLU; methyl-[5-(4-fluorbenzoyl)-1H-benzimidazole-2-y1]-carbamate) is another benzimidazole compound with anthelmintic activity. The biotransformation of FLU is extensive and follows similar metabolic pathways in various animal species. Ketoreduction and carbamate hydrolysis are the major phase I metabolic pathways in birds, pigs or sheep $[14,15]$. The structure of FLU and its reduced (FLU-R) and hydrolyzed (FLU-H) metabolites are shown in [16]. Identical biotransformation pathways have been described for mebendazole-another benzimidazole anthelmintic (FLU-like structure lacking the fluorine atom). Reduction of the carbonyl group is generally considered a deactivation pathway protecting organisms against the toxic effect of re- 
active aldehydes and ketones. Because reduced mebendazole lacks any anthelmintic activity [17, 18], FLU reduction probably also represents deactivation. However, no exact information about the anthelmintic activity of reduced flubendazole is available.

Pathological consequences of dicrocoeliosis may significantly alter the detoxification of anthelmintics due to changes in expression and biotransformation enzyme activities. The present study was focused on the determination and comparison of activities of the main biotransformation enzymes, ABZ and FLU hepatic metabolism in non-infected mouflons and in mouflons with dicrocoeliosis. The aim of this study was to evaluate the pharmacological and toxicological consequences of dicrocoeliosis in the liver tissue of mouflon. Furthermore, ultimate knowledge of drug biotransformation is necessary for a safe consumption of animal products.

\section{MATERIALS AND METHODS}

\subsection{Chemicals}

Albendazole was purchased from Sigma-Aldrich (Prague, Czech Republic). Albendazole sulfoxide and albendazole sulfone were obtained from Toronto Research Chemicals Inc. (Toronto, Canada). Flubendazole and its two main metabolites (reduced flubendazole, hydrolysed flubendazole) were provided by Janssen Pharmaceutica (Prague, Czech Republic). All other chemicals (HPLC or analytical grade) were obtained from Sigma-Aldrich.

\subsection{Animals and Biological Material}

Old mouflon ewes (Ovis musimon, 5-7 years-old) bred in Janovice and Vlkov game-parks in Czech Republic were used. At the beginning of winter season (2-3 months before the experiment), all mouflons in game-parks were collectively orally treated with ivermectin in order to eliminate the round worms totally, according to our previous experience [19]. The animals were not subjected to any other pharmacological administrations. Animals in the first group (noninfected, $n=3$ ) were coprologically negative, and the second group (D-infected, $n=4$ ) comprised fluke positive animals (EPG ranged between 480 and 1020 and adult flukes between 150 and 400); measurements carried out as described in [20]. No other endoparasitic infection was detected in the D-infected group. Mouflons were culled according to Czech slaughtering rules for farm animals (stunning, exsanguination) in February and March. The liver of mouflons from both groups were taken out immediately, sliced $(1 \mathrm{~cm}$ in thickness), washed repeatedly and pressed gently in physiological solution to remove blood and flukes (infected group). Slices of the left liver lobes were cut into smaller pieces and stored in liquid nitrogen during the transport to laboratory. The study was approved by Ethical Committee of Charles University, Czech Republic.

\subsection{Preparation of Subcellular Fractions}

Frozen pieces of liver were thawed at laboratory temperature (up to 15 minutes) and homogenised at the $\mathrm{w} / \mathrm{v}$ ratio of 1:6 in $0.1 \mathrm{M}$ sodium phosphate buffer, $\mathrm{pH} 7.4$, using a Potter-Elvehjem homogeniser and sonication with Sonopuls (Bandeline, Germany). The microsomal and cytosolic fractions were isolated by fractional ultracentrifugation of the tissue homogenate in the same buffer. A re-washing step (followed by a second ultracentrifugation) was included at the end of the microsomes preparation procedure. Microsomes, finally resuspended in a buffer containing $20 \%$ glycerol $(\mathrm{v} / \mathrm{v})$, and cytosol were stored at $-80^{\circ} \mathrm{C}$. Protein concentrations were assayed using the bicinchoninic acid method according to the Sigma protocol.

\subsection{Enzyme Assays}

Each enzyme assay was performed in triplicate for each animal. The amount of organic solvents in the final reaction mixture did not exceed $0.1 \%(\mathrm{v} / \mathrm{v})$.

The cytochrome P450 (CYP1A and 3A), 7ethoxyresorufin (EROD), 7-methoxyresorufin (MROD) and benzyloxyresorufin (BROD) $O$-dealkylase activities were determined using fluorimetric determination of resorufin [21] at $37^{\circ} \mathrm{C}$. Each substrate (dissolved in dimethylsulfoxide, DMSO) was added at a final concentration of $2.5 \mu \mathrm{M}$. The amount of microsomal protein in the reaction mixture ranged between 0.30-0.35 mg. Assays were conducted using a Perkin-Elmer luminescence spectrophotometer LS 50B, $\lambda_{\mathrm{EX}}=530 \mathrm{~nm}$ and $\lambda_{\mathrm{EM}}=585 \mathrm{~nm}$. The product formation was monitored continuously during 3 minutes. The EROD, MROD and BROD activities were calculated using the standard amount-addition technique.

$6 \beta$-Testosterone hydroxylase activity $(6 \beta-\mathrm{TOH})$, ascribed mainly to CYP3A, was assayed using high performance liquid chromatography (HPLC) [22]. The final concentration of substrate (dissolved in methanol) was $1 \mathrm{mM}$ and the amount of microsomal protein was $1.2-1.4 \mathrm{mg}$.

The 7-methoxy-4-trifluoromethylcoumarin demethylase (MFCD) activity and activity of flavine monooxygenases (FMO) were determined as described in our previous study [10].

The activities of reductases of carbonyl group were tested using the following substrates: 4-pyridincarboxaldehyde, metyrapone (dissolved in redistilled water) and DL-glyceraldehyde (dissolved in dimethylsulfoxide). Activity towards all of these substrates were measured in cytosolic samples, in microsomes were tested only activity towards 4-pyridincarboxaldehyde and metyrapone. The concentrations of substrates were $1 \mathrm{mM}$ (for DL-glyceraldehyde it was $10 \mathrm{mM}$ ), concentrations of NADPH were $0.1 \mathrm{mM}(0.3 \mathrm{mM}$ for DL-glyceraldehyde). Potassium phosphate buffer $\mathrm{pH} 6.0$ was used. $50 \mu \mathrm{L}(10 \mu \mathrm{L}$ for 4-pyridincarboxaldehyde) of enzyme volume (protein content 116-900 $\mu \mathrm{g}$ ) was added into $1 \mathrm{~mL}$ reaction mixture. Spectrophotometric determination (detection wavelength $340 \mathrm{~nm}, 25^{\circ} \mathrm{C}$ ) of NADPH consumption in the reaction mixture served for the assessment of reductase activities [23-26].

The enzyme activities for the model substrate 1acenaphthenol (substrate of aldo/keto reductases/dehydrogenases) were determined using methods described by Palackal et al. [25] with modifications. The velocity of substrate dehydrogenation was determined spectrophotometrically by measuring the change in absorbance of the cofactor nicotinamide adenine dinucleotide phosphate oxidized form $\left(\mathrm{NADP}^{+}\right)$at $340 \mathrm{~nm}$. The final $1.0 \mathrm{~mL}$ system contained 1 $\mathrm{mM}$ acenaphthenol dissolved in DMSO (1\% of organic sol- 
vent in final mixture), $1.0 \mathrm{mM} \mathrm{NADP}{ }^{+}, 50 \mu 1$ of cytosol and 0.1 M TRIS-HCl buffer ( $\mathrm{pH} 8.9$ ).

Oracin reductases were assayed as described [27]. Briefly, cytosolic and microsomal fraction $(100 \mu \mathrm{L})$ were incubated with $0.33 \mathrm{mM}$ oracin and $1 \mathrm{mM} \mathrm{NADPH}$ in total buffer volume of $0.3 \mathrm{~mL}$. Incubations $\left(37^{\circ} \mathrm{C}, 30 \mathrm{~min}\right)$ were terminated by cooling and alkalization, the incubates were liquid-liquid extracted into ethyl acetate. The extracts were evaporated to dryness and residues were dissolved in the mobile phase prior to the HPLC injection. The HPLC separation of oracin and dihydrooracin was performed using a $250 \mathrm{x} 4 \mathrm{~mm}$ BDH Hypersil column. The mobile phase was prepared by mixing the buffer $(10 \mathrm{mM}$, hexansulphonane, containing $0.1 \mathrm{M}$ triethylamine, $\mathrm{pH} 3.27$ set by $\mathrm{H}_{3} \mathrm{PO}_{4}$ ) with acetonitrile (ratio 3:1, v/v). HPLC separation was performed at $25^{\circ} \mathrm{C}$ with a flow rate of 1.5 $\mathrm{mL} / \mathrm{min}$. Dihydrooracin was detected with fluorescence detector using $\lambda_{\mathrm{Ex}}=340 \mathrm{~nm}$ and $\lambda_{\mathrm{EM}}=418 \mathrm{~nm}$. Oracin was detected with UV-VIS detector at a detection wavelength of $280 \mathrm{~nm}$.

The microsomal UDP-glucuronosyltransferase (UGT) activity was assayed following the method by Mizuma et al. [28]. Microsomes were preincubated with a Slovasol detergent at $4^{\circ} \mathrm{C}$ for 20 minutes. The reaction mixture (total volume of $0.1 \mathrm{~mL}$ ) contained $10 \mu \mathrm{L}$ of microsomes $(0.12-0.14$ $\mathrm{mg}$ of protein), $0.33 \mathrm{mM}$ UDP-glucuronic acid, $166.8 \mu \mathrm{M} p$ nitrophenol (dissolved in re-distilled water) in $0.1 \mathrm{M}$ Tris/ $\mathrm{HCl}$ buffer (pH 7.4). After 20 minutes of incubation at $37^{\circ} \mathrm{C}$, the reaction was stopped by addition of $50 \mu \mathrm{L}$ of $3 \%$ trichloroacetic acid $(\mathrm{v} / \mathrm{v})$. After shaking and centrifugation (3 min., $5000 \mathrm{rpm}$ ), $50 \mu \mathrm{L}$ of the supernatant were mixed with $50 \mu \mathrm{L}$ of $1 \mathrm{M} \mathrm{NaOH}$. The absorbance was measured using a BioRad microplate reader (detection wavelength of $415 \mathrm{~nm}$ ).

The cytosolic glutathione-S-transferase (GST) activities were assayed using 1-chloro-2,4-dinitrobenzene as a substrate (dissolved in ethanol). The reaction mixture (total volume $1 \mathrm{~mL}$ ) contained $10 \mu \mathrm{L}$ of cytosol (0.14-0.18 mg of protein), $1 \mathrm{mM}$ reduced glutathione, $1 \mathrm{mM}$ 1-chloro-2,4dinitrobenzene in $0.1 \mathrm{M}$ Na-phosphate buffer ( $\mathrm{pH}$ 6.5). The reaction mixture was shaked and than the absorbance was measured spectrophotometrically at $340 \mathrm{~nm}$ four times in minute intervals.

\subsection{Incubation of Microsomes with $A B Z$ and $A B Z S O$}

The hepatic microsomal fractions were incubated with either ABZ $(0.5-25 \mu \mathrm{M})$ or rac-ABZSO $(0.5-25 \mu \mathrm{M})$. The reaction mixture (total volume of $0.3 \mathrm{~mL}$ ) contained $100 \mu \mathrm{L}$ of microsomal suspension containing 1.1-1.4 $\mathrm{mg}$ of proteins, NADPH (1 mM) and 0.1 M Na-phosphate buffer (pH 7.4). The blank samples contained $100 \mu \mathrm{L}$ of $0.1 \mathrm{M}$ sodium phosphate buffer ( $\mathrm{pH}$ 7.4) instead of microsomes. The incubations were carried out at $37^{\circ} \mathrm{C}$ for $60 \mathrm{~min}$ under aerobic conditions. The product formation was linear up to 60 minutes. The incubation was stopped by cooling and by an addition of $30 \mu \mathrm{L}$ of concentrated ammonium solution. In the next step, $700 \mu \mathrm{L}$ of ethyl acetate were added, shaken ( 2 min., vortex) and centrifuged ( 3 min., $5000 \mathrm{rpm}$ ). Six hundred $\mu \mathrm{L}$ of the organic layer were taken up, evaporated using an Eppendorf 5310 concentrator and analysed using HPLC.

\subsection{Incubation of Microsomes and Cytosol with FLU}

The cytosolic and microsomal fractions were incubated with FLU $(0.5-25 \mu \mathrm{M})$ under the same conditions as de- scribed in paragraph 2.5. The cytosolic fraction contained $1.4-1.8 \mathrm{mg}$ of proteins in reaction mixture.

\subsection{HPLC Analysis of $A B Z$ and its Metabolites}

Achiral HPLC analysis was carried out using a Shimadzu LC-10ADvp solvent delivery module, a Shimadzu SIL10ADvp autoinjector, a Shimadzu RF-10Axl fluorescence detector $\left(\lambda_{\mathrm{EX}}=290 \mathrm{~nm}, \lambda_{\mathrm{EM}}=320 \mathrm{~nm}\right)$, a Shimadzu CTO10ACvp column oven fitted with a LiChroCART 250-3 (LiChrospher 60 RP-select B, $250 \mathrm{~mm} \times 3 \mathrm{~mm}, 5 \mathrm{~m}$ ) reversephase HPLC column (Hewlett Packard, USA) equipped with LiChroCART 4-4 (LiChrospher 60 RP-select B, 4 mm x 4 $\mathrm{mm}, 5 \mathrm{~m}$ ) guard column (Merck, Germany). The mobile phase A consisted of acetonitrile- $25 \mathrm{mM}$ potassium phosphate buffer $(\mathrm{pH} 3.0 ; 1: 2, \mathrm{v} / \mathrm{v})$. The flow rate was 0.5 $\mathrm{mL} / \mathrm{min}$ in isocratic mode. All experiments were carried out at $25^{\circ} \mathrm{C}$. Data were processed using the Shimadzu Class VP integrator software, version $6.12 \mathrm{SP} 2$. The compounds were identified according to the retention times of respective reference standards. Under these chromatographic conditions, the retention times were $5.3 \mathrm{~min}(\mathrm{ABZSO}), 7.4 \mathrm{~min}(\mathrm{AB}-$ $\mathrm{ZSO}_{2}$ ), and $17.3 \mathrm{~min}(\mathrm{ABZ})$.

\subsection{HPLC Separation of ABZSO Enantiomers}

During the reverse phase HPLC analysis, the ABZSO fractions were collected into vials. The collected fractions were evaporated to dryness using Eppendorf 5310 concentrator and redissolved in $200 \mathrm{~L}$ of $0.2 \%$ 2-propanol in water $(\mathrm{v} / \mathrm{v})$. The mobile phase B consisted of 2-propanol-0.01 M phosphate buffer solution ( $\mathrm{pH} 6.9 ; 0.2: 99.8, \mathrm{v} / \mathrm{v})$.

One hundred $\mathrm{L}$ of each sample were injected into a Shimadzu HPLC system fitted with a Chiral-AGP column (150 mm $\times 4 \mathrm{~mm}, 5 \mathrm{~m})$, equipped with Chiral-AGP guard column (10 mm x $4 \mathrm{~mm}, 5 \mathrm{~m}$; both ChromTech, Hägersten, Sweden). The flow rate of the mobile phase B was 0.9 $\mathrm{mL} / \mathrm{min}$. All experiments were carried out at $25^{\circ} \mathrm{C}$. This chiral chromatographic method was adapted from that described previously by Delatour et al. [8]. The retention time was $6.3 \mathrm{~min}$ for (-)-ABZSO and $18.6 \mathrm{~min}$ for (+)-ABZSO. The ABZSO enantiomers were determined according to reference above mentioned [8].

\subsection{HPLC Analysis of FLU and its Metabolites}

Chromatographic analyses were performed with the same chromatograph and column as described for analysis of ABZ metabolites. The mobile phase was a mixture of acetonitrile and $25 \mathrm{mM}$ potassium phosphate buffer $(\mathrm{pH} 3.0 ; 3: 7, \mathrm{v} / \mathrm{v})$ delivered at a flow rate of $0.7 \mathrm{~mL} / \mathrm{min}$ in isocratic mode. The temperature was $25^{\circ} \mathrm{C}$. Using the photodiode array detector, chromatograms were recorded at $246 \mathrm{~nm}$ and $300 \mathrm{~nm}$ (scan 195-380 nm), spectrofluorimetric detector $\left(\lambda_{\mathrm{EX}}=290 \mathrm{~nm}\right.$, $\lambda_{\mathrm{EM}}=320 \mathrm{~nm}$ ). FLU-H, FLU-R, albendazole (I.S.) and FLU were detected with the photodiode array detector. The spectrofluorimetric detector served for improving the sensitivity of FLU-R detection (FLU-H and FLU are not fluorescent). Under these chromatographic conditions, the retention times were $5.2 \mathrm{~min}$ (FLU-H), $6.2 \mathrm{~min}$ (FLU-R), $17.5 \mathrm{~min}$ (ABZ as IS) and $23.3 \mathrm{~min}$ (FLU).

\subsection{HPLC Separation of FLU-R Enantiomers}

The chromatographic method used for the determination of flubendazole and its two metabolites has been described 
previously [16]. The chromatographic system was composed of an SCM1000 solvent degasser, a P4000 quaternary gradient pump, an AS3000 autosampler with a $100 \mu \mathrm{L}$ sample loop, an UV6000 LP photodiode array detector (UV143 PDA) with Light Pipe Technology, an SN4000 system controller and a data station with the ChromQuest 4 analytical software. Daicel chiral column (250 $\mathrm{mm}$ x $4.6 \mathrm{~mm})$ packed with Chiralcel OD-R (Daicel Chemical Industries Ltd., Japan) and mobile phase consisting of acetonitrile - $1 \mathrm{M}$ aqueous $\mathrm{NaClO}_{4}(4: 6, \mathrm{v} / \mathrm{v})$ were employed for chiral chromatographic separations. The flow rate was $0.5 \mathrm{~mL} / \mathrm{min}$. UV detection was performed in dual wavelength mode (246 and $300 \mathrm{~nm})$. The retention time was $13.9 \mathrm{~min}$ for (-)-FLU-R and $16.5 \mathrm{~min}$ for (+)-FLU-R.

\subsection{Statistical Analysis}

Student's t-test and Mann-Whitney test was used for the statistical evaluation of differences between non-infected animals and animals with dicrocoeliosis. A probability of $p$ 0.05 was considered significant.

\section{RESULTS}

\subsection{Effect of dicrocoeliosis on In Vitro Activities of He- patic Biotransformation Enzymes}

Several enzyme activities corresponding to the main isoforms of cytochrome P450 (CYPs) were measured in hepatic microsomes isolated from the non-infected and D-infected animals (Table 1). Microsomes from the infected animals exhibited lower MROD and MFCD activity when compared with microsomes from the non-infected animals. These changes were only slight and the statistical significance was not proved due to large inter-individual differences. A significant difference was observed in $6 \beta-\mathrm{TOH}$ activity: the mean decrease in hepatic microsomes of the infected animals was $42 \%$. Both experimental groups did not differ in other CYP activities (EROD and BROD) that were tested.

TBSO activity is mainly ascribed to flavine monooxygenases (FMO). The values of TBSO activity in the noninfected and infected mouflons are presented in Table 1. The TBSO microsomal activities of infected and non-infected mouflons did not differ significantly from each other.
As for the conjugation enzyme activities, glucuronidation of p-nitrophenol and glutathione-S-transferase activity towards 1-chloro-2,4-dinitrobenzene were assayed. Both activities showed significant decrease in infected mouflons (37\% in UGT and $27 \%$ in GST, respectively).

Measured activities towards substrates of reductases/ dehydrogenases are summarized in Table 2 . Slight but significant decrease $(16 \%)$ in cytosolic acenaphtenol dehydrogenase activity was found in D-infected animals. On the other hand, dicrocoeliosis caused a mild increase in activity of microsomal pyridincarboxaldehyde reductase and cytosolic oracin reductases. The activities of microsomal oracin reductases were almost two-fold higher in the infected group than in the non-infected animals.

\subsection{Effect of Dicrocoeliosis on In Vitro Metabolism of ABZ}

To compare the velocity of ABZ oxidative biotransformation, $\mathrm{ABZ}$ (at various concentrations) was incubated with nicotinamide adenine dinucleotide phosphate (NADPH) and hepatic microsomes of non-infected or D-infected mouflons. The concentrations of $\mathrm{ABZ}, \mathrm{ABZSO}$ and $\mathrm{ABZSO}_{2}$ were determined using HPLC (Fig. 1A,B). As ABZSO exists in two enantiomeric forms, a chiral stationary phase was used for the separation of the ABZSO enantiomers. In blank samples (without microsomes), no ABZ metabolite was detected. In mouflon liver, ABZ oxidation was stereospecific, with preferential formation of $(+)$-ABZSO. Comparing the both experimental groups, an insignificant shift in the ABZSO enantiomeric ratio $((+)-\mathrm{ABZSO} /(-)-\mathrm{ABZSO}))$ was observed: from 1.5 in the non-infected animals to 1.7 in the infected animals. In both animal groups, the ABZSO to $\mathrm{ABZSO}_{2}$ conversion exhibited practically the same velocity.

Table 3 shows apparent kinetic parameters (calculated by the GraphPad Prism program, according to MichaelisMenten kinetics). The apparent kinetic parameters, maximal velocity $\left(\mathrm{V}^{\prime}{ }_{\max }\right)$ and Michaelis constant $\left(\mathrm{K}_{\mathrm{m}}^{\prime}\right)$, of the $\mathrm{ABZ}$ conversion (both first and second step of sulfoxidation) were significantly lower in the D-infected group than in the noninfected group. Although the reaction of non-infected animals displayed higher maximal velocity, the microsomal metabolizing enzymes from D-infected animals showed

Table 1. Specific Activities of Biotransformation Enzymes Tested in Hepatic Microsomes or Cytosole from Non-Infected Mouflons or Mouflons with Dicrocoeliosis

\begin{tabular}{|c|c|c|}
\hline Specific Activity & Non-Infected & Dicrocoelium-Infected \\
\hline EROD (pmol/min/mg of proteins) & $41.2 \pm 1.0$ & $37.3 \pm 8.2$ \\
\hline BROD (pmol/min/mg of proteins) & $11.6 \pm 1.8$ & $13.3 \pm 1.1$ \\
\hline MFCD (nmol $/ \mathrm{min} / \mathrm{mg}$ of proteins) & $0.40 \pm 0.12$ & $0.27 \pm 0.14$ \\
\hline TBSO (nmol/min/mg of proteins) & $2.01 \pm 0.53$ & $2.04 \pm 037$ \\
\hline pn-UGT (nmol/min/mg of proteins) & $7.13 \pm 0.59$ & $4.52 \pm 0.76^{*}$ \\
\hline GST $(\mu \mathrm{mol} / \mathrm{min} / \mathrm{mg}$ of proteins) & $0.72 \pm 0.12$ & $0.53 \pm 0.14 *$ \\
\hline
\end{tabular}

Data represent the mean \pm SD from 3 non-infected animals and 4 D-infected animals. Each sample was made in triplicate ( $\mathrm{n}=9$, resp.12).

*Significant difference $(\mathrm{p}<0.05)$ between non-infected and D-infected animals. 
Table 2. Specific Activities (nmol/min/mg of Proteins) of Reductases/Dehydrogenases Tested in Hepatic Microsomes or Cytosol from Non-Infected Mouflons or Mouflons with Dicrocoeliosis

\begin{tabular}{|c|c|c|c|c|}
\hline \multirow{3}{*}{ Substrate } & \multicolumn{4}{|c|}{ Specific Activity [nmol/min/mg of Protein] } \\
\hline & \multicolumn{2}{|c|}{ Cytosol } & \multicolumn{2}{|c|}{ Microsomes } \\
\hline & Non-Infected & Infected & Non-Infected & Infected \\
\hline DL-glyceraldehyde & $0.33 \pm 0.02$ & $0.32 \pm 0.05$ & ND & \\
\hline 4-pyridincarboxaldehyde & $0.89 \pm 0.03$ & $0.90 \pm 0.14$ & $0.20 \pm 0.04$ & $0.23 \pm 0.04 *$ \\
\hline 1-acenaphthenol & $1.50 \pm 0.33$ & $1.27 \pm 0.24 *$ & ND & \\
\hline metyrapon & nd & & $0.08 \pm 0.05$ & $0.09 \pm 0.03$ \\
\hline oracin & $0.6 \pm 0.02$ & $0.7 \pm 0.09 *$ & $0.006 \pm 0.001$ & $0.01 \pm 0.005 *$ \\
\hline
\end{tabular}

Data represent the mean \pm SD from 3 non-infected animals and 4 D-infected animals. Each sample was made in triplicate $(\mathrm{n}=9$, resp. 12$)$.

ND: Not determined.

nd: Not detected.

*Significant difference $(\mathrm{p}<0.05)$ between non-infected and D-infected animals.

(A)

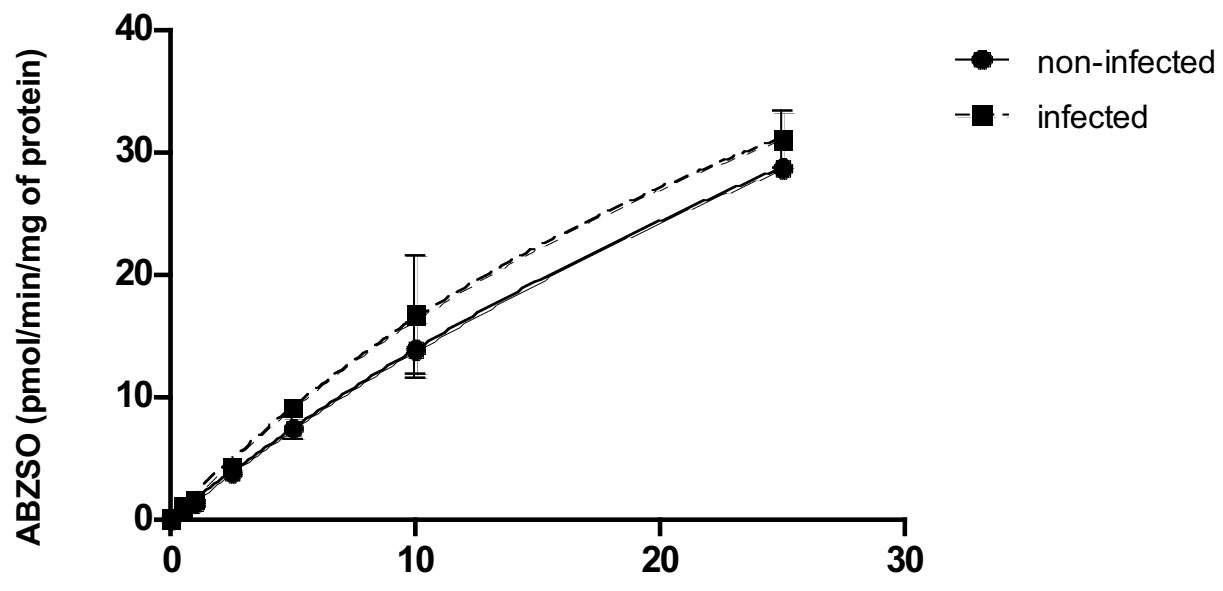

$A B Z(\mu M)$

(B)

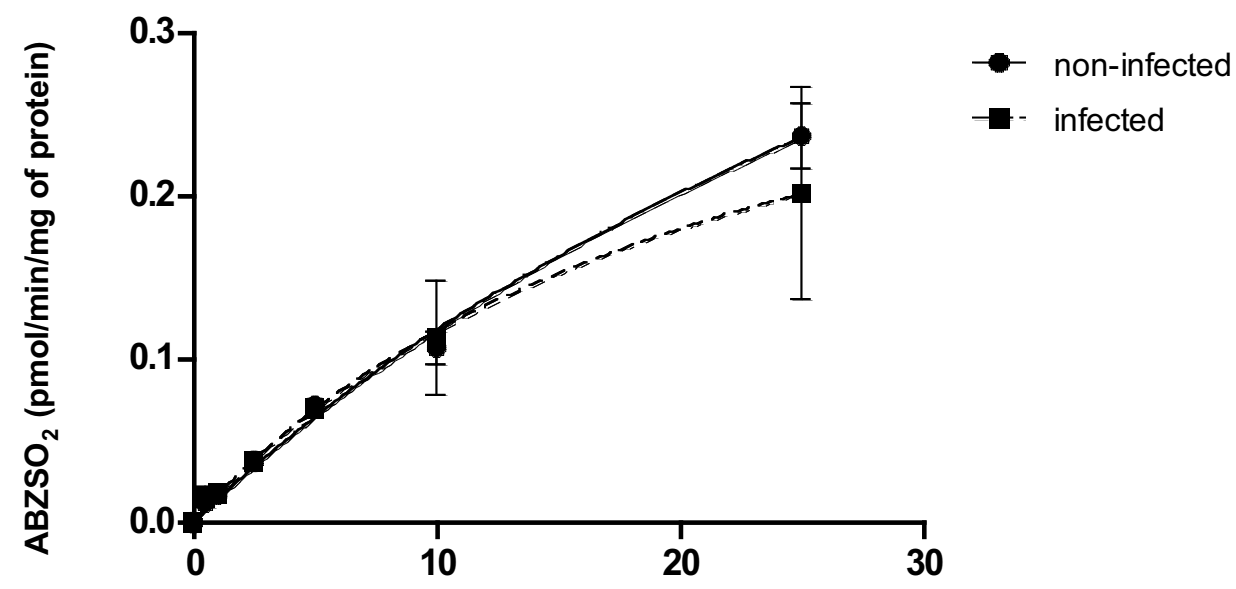

$\operatorname{ABZ}(\mu M)$

Fig. (1). Velocity of formation of $\mathrm{ABZSO}(\mathbf{A})$ or $\mathrm{ABZSO}_{2}(\mathbf{B})$ in dependence of substrate $\mathrm{ABZ}$ concentration in hepatic microsomes from non-infected mouflons and mouflons with dicrocoeliosis. Mixtures of microsomes from 3 non-infected animals and 4 D-infected animals were used. Each sample was made in triplicate. 
Table 3. Apparent Kinetic Parameters $V^{\prime}{ }_{\max }(\mathrm{nM} / \mathrm{min})$ and $K_{m}^{\prime}(\mu M)$ of ABZ, ABZSO, and FLU Biotransformation Determined in Hepatic Microsomes (m) and Cytosole (c) of Non-Infected Mouflons and Mouflons with Dicrocoeliosis

\begin{tabular}{|c|c|c|c|c|c|}
\hline Substrate & Localisation & Reaction & Parameters & Non-Infected & Infected \\
\hline $\mathrm{ABZ}$ & $\mathrm{m}$ & $\begin{array}{l}\mathrm{ABZ} \rightarrow \mathrm{ABZSO} \\
\mathrm{ABZ} \rightarrow(\mathrm{ABZSO}) \rightarrow \mathrm{ABZSO}_{2}\end{array}$ & $\begin{array}{l}\mathrm{V}_{\text {max }}^{\prime} \\
\mathrm{K}_{\mathrm{m}}^{\prime} \\
\mathrm{V}_{\text {max }}^{\prime} \\
\mathrm{K}_{\mathrm{m}}^{\prime}\end{array}$ & 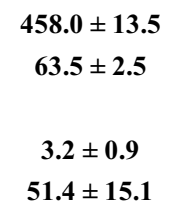 & $\begin{array}{c}323.1 \pm 19.1^{*} \\
37.6 \pm 3.3^{*} \\
1.7 \pm 0.4^{*} \\
23.5 \pm 2.7^{*}\end{array}$ \\
\hline ABZSO & $\mathrm{m}$ & $\mathrm{ABZSO} \rightarrow \mathrm{ABZSO}_{2}$ & $\begin{array}{l}\mathrm{V}_{\text {max }}^{\prime} \\
\mathrm{K}_{\mathrm{m}}^{\prime} \\
\end{array}$ & $\begin{array}{c}9.0 \pm 1.4 \\
30.2 \pm 7.5\end{array}$ & $\begin{array}{c}9.1 \pm 2.5 \\
35.7 \pm 14.3 \\
\end{array}$ \\
\hline FLU & $\begin{array}{l}\mathrm{c} \\
\mathrm{m}\end{array}$ & $\begin{array}{l}\text { FLU } \rightarrow \text { FLU-R } \\
\text { FLU } \rightarrow \text { FLU-R }\end{array}$ & $\begin{array}{l}\mathrm{V}_{\text {max }}^{\prime} \\
\mathrm{K}_{\mathrm{m}}^{\prime} \\
\mathrm{V}_{\text {max }}^{\prime} \\
\mathrm{K}_{\mathrm{m}}^{\prime}\end{array}$ & $\begin{array}{c}\mathbf{3 8 8 . 0} \pm \mathbf{1 0 3 . 9} \\
45.4 \pm 17.2 \\
\\
7.7 \pm 0.5 \\
\mathbf{1 5 . 6} \pm \mathbf{2 . 2}\end{array}$ & $\begin{array}{c}\mathbf{2 3 8 . 4} \pm \mathbf{3 6 . 2 *} \\
31.8 \pm 7.5 \\
6.6 \pm 0.8 \\
\mathbf{2 5 . 7} \pm \mathbf{4 . 9 *}\end{array}$ \\
\hline
\end{tabular}

higher substrate affinity. The velocity of ABZSO formation was considerably higher compared with $\mathrm{ABZSO}_{2}$ formation.

No metabolites were detected in the cytosolic incubations with either ABZ or ABZSO.

\subsection{Effect of Dicrocoeliosis on In Vitro Metabolism of ABZSO}

To study the ABZSO sulfoxidation in the microsomal incubations, rac-ABZSO was used as a substrate. In blank samples (without microsomes), no ABZSO metabolite was detected and no changes of ABZSO enantiomeric ratio were found. No difference in the velocity of $\mathrm{ABZSO}_{2}$ formation in the microsomal incubations of D-infected and non-infected mouflons was observed (Fig. 2). Also the kinetic parameters remained unchanged (see Table 3). The conversion of ABZSO to ABZ was not detected.

\subsection{Effect of Dicrocoeliosis on In Vitro Metabolism of FLU}

For the study of FLU biotransformation, FLU (at various concentrations) was incubated with NADPH and each of hepatic subcellular fractions of non-infected or infected mouflons. The concentration of FLU and its metabolites was determined using HPLC. Only one metabolite, FLU-R, was detected. Comparing both groups, the velocities of FLU-R formation were similar and a significant difference was observed at higher substrate concentrations only (Fig. 3A,B). As FLU-R exists in two enantiomeric forms, a chiral stationary phase was used for their separation. In the in vitro incubation of cytosol with FLU, (+)-FLU-R was the prevailing enantiomer and only traces of (-)-FLU-R were detected. In microsomal incubations, the extent of FLU-R formation was significantly lower than in cytosol. The maximal FLU-R formation velocity in cytosole differed significantly between the non-infected and the infected animals: the FLU metabo-

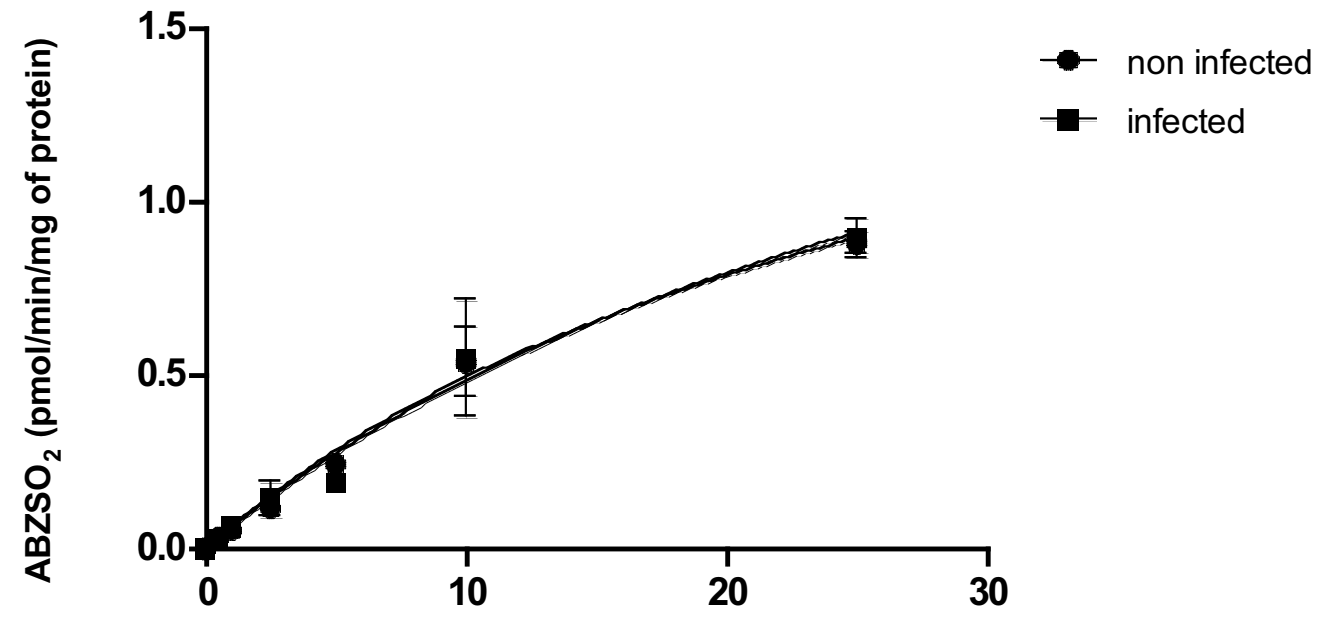

ABZSO $(\mu \mathrm{M})$

Fig. (2). Velocity of formation of $\mathrm{ABZSO}_{2}$ in dependence of substrate rac-ABZSO concentration in hepatic microsomes from non-infected mouflons and mouflons with dicrocoeliosis. Mixtures of microsomes from 3 non-infected animals and 4 D-infected animals were used. Each sample was made in triplicate. 
lization in the infected group was less intensive (see Table 3).

\section{DISCUSSION}

Parasitic infections can modify host's ability to metabolize drugs by altering the biotransformation enzymes, and these changes may have various pharmacological, toxicological or physiological consequences. As drug metabolism occurs predominantly in the liver, those parasites that occupy sites in this organ, such as Fasciola spp. or Dicrocoelium spp., tend to be the ones with the greatest effects on the host's ability to metabolize drugs. These effects can modify the host's response to substances unrelated to the infection and to drugs that are administered under a chemotherapeutic regime. However, most pharmacokinetic and biotransformation studies have been performed in healthy animals and a potential of infection to change the condition of the organism has not been considered $[29,30]$.
Regarding parasitism, a significant decrease in the activities of all drug metabolizing enzymes in the infected animals was proposed [31]. Later studies revealed that the effect of parasitism is not very unambiguous. Although in rats the single infection caused by Fasciola hepatica decreased all activities of drug metabolizing enzymes that were tested, most of these activities did not change under repetitive fluke infections. Moreover, CYP3A and CYP1A activities increased [32]. In sheep, Fasciola hepatica infection (single or bi-infection) downregulated the CYP3A expression and activity in hepatic microsomes, but the GST activity in hepatic cytosol remained unchanged $[33,34]$. Schistosoma mansoni infection increased the production of aflatoxin B-1 metabolites formed by the action of human microsomal monooxygenases [35]. Moreover, Schistosoma mansoni infection caused a significant enhancement of CYP1A activity in the liver microsomes in mice $[36,37]$. On the other hand, alterations of murine hepatic CYPs in early (acute) Schistosoma

(A)

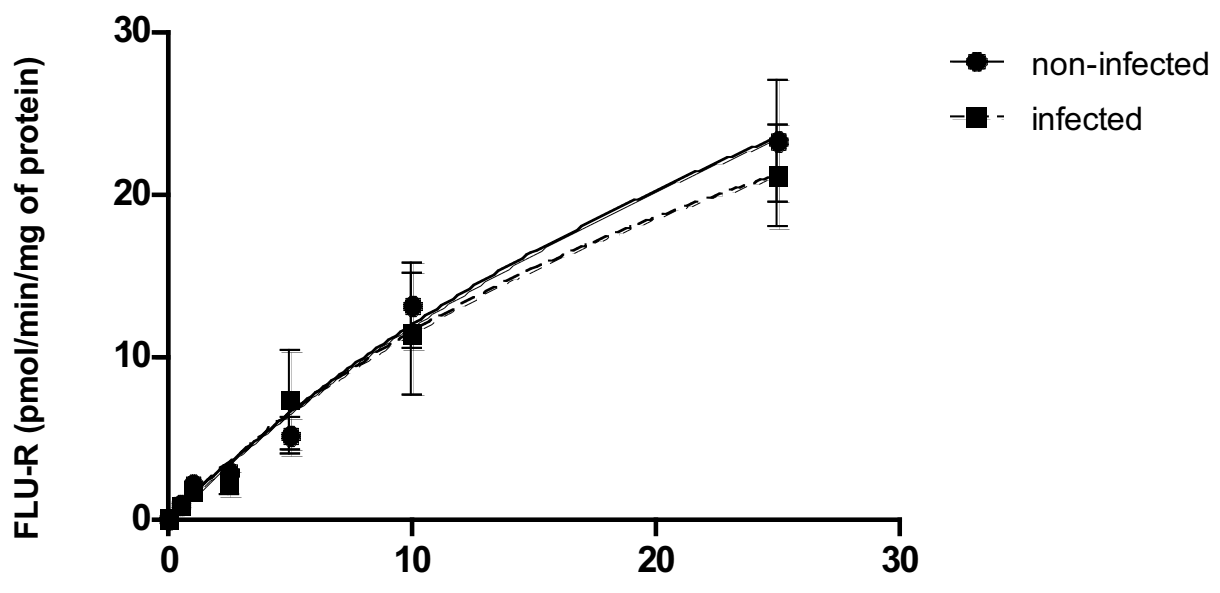

FLU ( $\mu M)$

(B)

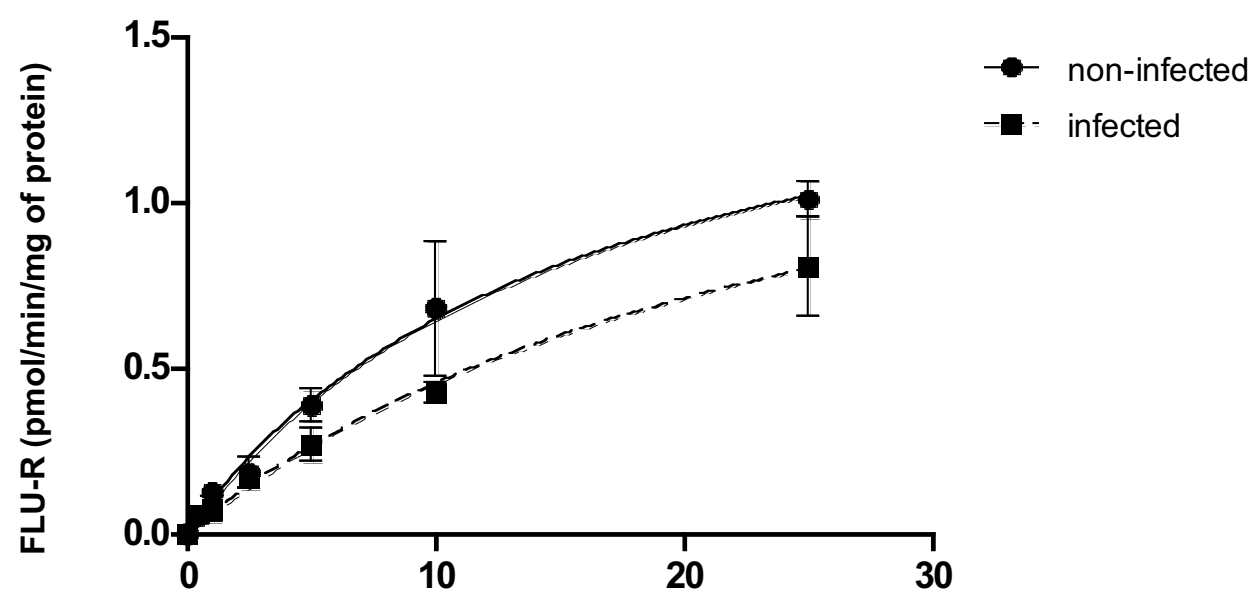

$\operatorname{FLU}(\mu \mathrm{M})$

Fig. (3). Velocity of formation of FLU-R in dependence of substrate FLU concentration in hepatic cytosol (A) and microsomes (B) from non-infected mouflons and mouflons with dicrocoeliosis. Mixtures of cytosole from 3 non-infected animals and 4 D-infected animals were used. Each sample was made in triplicate. 
mansoni infection were mild, or even nonexistent [38]. Infection of mice with low levels of Schistosoma mansoni cercariae increased GST activity while severe infection significantly diminished such activity [39].

Not only the extent of parasitoses, but also the age and sex of animals and the duration of parasitoses may affect the changes in biotransformation enzymes evocated by parasitic infection. With respect to these facts, two consecutive studies comparing the metabolism of anthelmintics and biotransformation enzyme activities in animals with dicrocoeliosis and in the non-infected ones were carried out. In our previous study [10], young (11-13 months old) mouflon rams were used while in the present study, two groups of old mouflon ewes - non-infected and D-infected-were compared. In young mouflons only two enzyme activities were significantly affected by dicrocoeliosis (increased TBSO activity and decreased GST activity) but in old mouflons further changes in enzyme activities caused by the long term exposure to parasitic diseases were observed.

In the present study, cytochromes P450, flavin monooxygenases, reductases/dehydrogenases and conjugation enzymes which participate in biotransformation of ABZ, ABZSO and FLU were investigated. Comparing the oxidising enzymes activities in both experimental groups of old mouflons, a significant decrease in $6 \beta-\mathrm{TOH}$ activity, corresponding mainly to the activity of CYP3A, was observed. In our previous study, dicrocoeliosis did not affect this activity in young animals. On the other hand, dicrocoeliosis did not cause the changes in TBSO activity (corresponding mainly to FMO) in old mouflons while in young infected mouflons a significant increase in TBSO activity was found. In old mouflons with dicrocoeliosis, the UGT as well as GST activities significantly decreased. The reduction in GST and UGT activities could cause a significant decrease in biotransformation of drugs which are predominantly metabolized by conjugation with glutathione or glucuronic acid. It may result in a slowdown in drug elimination, in prolonged drug presence in the body, thus increasing the risk of animal products drug contamination. This fact should be considered during the pharmacotherapy of infected food-producing animals.

Only slight differences were found when reductase/dehydrogenase activities in non-infected and D-infected animals were compared. An increase in conversion of oracin to dihydrooracin was observed in both subcellular fractions from D-infected animals as well as the activity of microsomal reductases towards 4-pyridincarboxaldehyde. A significant decrease in activities of acenaftenol dehydrogenases was observed in cytosol from the infected animals (compared with the non-infected animals). Such changes in expression and activity of the biotransformation enzymes may be caused by toxic effects of parasite excretion products or inflammation mediators.

From the pharmacological point of view, the study of the effect of parasitism directly on biotransformation of antiparasitic drugs is particularly important. In gerbils infected by Echinococcus granulosus, a higher plasma concentration of $\mathrm{ABZSO}_{2}$ after $\mathrm{ABZ}$ administration and an increased $\mathrm{ABZ}$ sulfoxidation in hepatic microsomes were found (compared with the control animals) [40]. On the other hand, a significant decrease in ABZ sulfonation during experimental fascioliosis in sheep in vivo as well as in vitro was reported
[41]. In our experiments, with $\mathrm{ABZ}$ as a substrate, dicrocoeliosis reduced the apparent maximal velocity $\left(\mathrm{V}^{\prime}{ }_{\max }\right)$ of $\mathrm{ABZSO}$ and $\mathrm{ABZSO}_{2}$ formation in incubations with microsomes. Generally, the first step of ABZ oxidation (sulfoxidation) proceeded much faster than the second step (sulfonation). The ABZ sulfoxidation is carried out by the FMO and CYP3A while sulfonation is catalyzed by CYP1A. Thus after the administration of ABZ to animals, the anthelmintically active ABZSO arises quickly and is only slowly metabolized by CYP1A to the anthelmintically inactive AB$\mathrm{ZSO}_{2} . \mathrm{V}_{\text {max }}^{\prime}$ of the ABZSO to $\mathrm{ABZSO}_{2}$ conversion was the same in non-infected animals as in fluke infected animals.

Stereospecificity of ABZ biotransformation was studied because two different enantiomeric forms of ABZSO, namely, (-)-ABZSO and (+)-ABZSO, may be formed by liver microsomes. Multiple enzymes participate in ABZSO enantiomer formation: CYP3A generates mainly (-)-ABZSO while the FMO produce (+)-ABZSO [10]. In domestic sheep and mouflon, $(+)$-ABZSO formation predominates [42, 43]. In our experiments, the (+)-ABZSO/(-)-ABZSO ratio shifted from 1.5 in the non-infected animals to 1.7 in the D-infected animals. This shift was probably caused by a decrease in (-)ABZSO formation due to a lowered CYP3A activity. This result is in a good agreement with the decreased $6 \beta-\mathrm{TOH}$ activity found.

Ketoreduction and carbamate hydrolysis represent the major phase I metabolic pathways of FLU in all species investigated [14]. Although no exact information about anthelmintic activity of FLU metabolites is available, reduction as well as hydrolysis of FLU probably results in its deactivation. In our in vitro study, only FLU-R was detected after incubation of hepatic subcellular fractions with FLU. In contrast, formation of both FLU metabolites (FLU-R, FLU-H) was described after intravenous or intraruminal administration of FLU to sheep [15]. Hydrolytic activity toward FLU may occur in tissues such as blood, plasma, lungs and kidney. Particularly the ruminal microflora is very active in hydrolytic metabolic reactions and may contribute to the FLU conversion into FLU-H. Formation of FLU-R occurred mainly in cytosolic samples and this reaction is almost highly stereospecific with (+)-FLU-R dominance. The velocity of FLU reduction was slightly (but significantly) lower in the D-infected animals compared with the non-infected animals.

The apparent maximal velocities $\left(\mathrm{V}^{\prime}{ }_{\max }\right)$ of product formation were lower in infected than non-infected animals in all enzymatic reactions tested. The apparent Michaelis constants $\left(\mathrm{K}_{\mathrm{m}}^{\prime}\right)$ were also decreased due to infection. $\mathrm{K}_{\mathrm{m}}^{\prime}$ changes may indicate an alteration in proportional participation of anthelmintics metabolising enzymes in microsomal and cytosolic multienzymatic systems. As both kinetic parameters similarly decreased, dicrocoeliosis did not affect the intrinsic clearance $\left(\mathrm{V}_{\max }^{\prime} / \mathrm{K}_{\mathrm{m}}^{\prime}\right)$ and thus a similar extent of biotransformation may be expected in the infected as well as non-infected animals.

\section{CONCLUSION}

Dicrocoeliosis in mouflons caused only slight (not pharmacologically important) changes in ABZ and FLU hepatic biotransformation. However, activities of both tested conjugation enzymes, namely glutathione-S-transferase and UDP- 
glukuronosyl transferase, were significantly decreased in infected mouflon ewes. This fact can be problematic because of the potential to impair elimination of many drugs, and should be taken into consideration in pharmacotherapy and pharmacoprophylaxis. Mouflon and domestic sheep are genetically very close. Genetic data provided a strong evidence for domestification of sheep from several mouflon subgroups [44]. Therefore the experimental data found in mouflon should be also valid for domestic sheep.

\section{ACKNOWLEDGEMENT}

Financial support of this project was provided by Grant Agency of Czech Republic, Grant No. 524/07/0611.

\section{REFERENCES}

[1] Hiepe T. Helminth control in sheep and goat flocks (in German, abstract in English). Tierarztlische Praxis 1994; 22: 29-34.

[2] Otranto D, Traversa D. A review of dicrocoeliosis of ruminants including recent advances in the diagnosis and treatment. Vet Parasitol 2002; 107: 317-335.

[3] Campo R, Manga-González MY, González-Lanza C. Relationship between egg output and parasite burden in lambs experimentally infected with different doses of Dicrocoelium dendriticum (Digenea). Vet Parasitol 1999; 87: 139-149.

[4] Braun U, Wolfensberger R, Hertzbrg H. Diagnosis of liver flukes in cows - a comparison of the findings in the liver, in the feces, and in the bile. Schweizer Archiv fur Tierheilkunde 1995; 137: 438444

[5] Jithendran KP, Vaid J, Krishna L. Comparative evaluation of agar gel precipitation, counter immunoelectrophoresis and passive haemagglutination tests for the diagnosis of Dicrocoelium dendriticum infection in sheep and goats. Vet Parasitol 1996; 61: 151-156.

[6] Otranto D, Traversa D. Dicrocoeliosis of ruminants: a little known fluke disease. Trends Parasitol 2003; 17: 12-15.

[7] Lamka J, Kří ová V, Cvilink V, et al. A single adulticide dose of albendazole induces cytochromes P4501A in mouflon (Ovis musimon) with dicrocoeliosis. Vet Med 2007; 52: 343-352.

[8] Delatour P, Benoit E, Garnier F, Besse S. Chirality of the sulphoxide metabolites of fenbendazole and albendazole in sheep. J Vet Pharmacol Therap 1990; 13: 361-366.

[9] Velík J, Baliharová V, Szotáková B, Wsól V, Lamka J. Stereospecific biotransformation of albendazole in mouflon and rat isolated hepatocytes. J Vet Pharmacol Therap 2003; 26: 297-302.

[10] Skálová L, Kř́i ová V, Cvilink V, et al. Mouflon (Ovis musimon) dicrocoeliosis: Effect of parasitosis on the activities of biotransformation enzymes and albendazole metabolism in liver. Vet Parasitol 2007; 146: 254-262.

[11] Moreno L, Echevarria F, Muñoz F, et al. Dose-dependent activity of albendazole against benzimidazole-resistant nematodes in sheep: relationship between pharmacokinetics and efficacy. Exp Parasitol 2004a; 106: 150-157.

[12] Cordero Del Campillo M, Rojo Vázquez FA, Diez Bañoz P, Chaton-Schaffner M. Albendazole efficiency against a natural Dicrocoelium dendriticum infestation in sheep. Rev Med Vet 1982; 133: 41-49.

[13] Schuster R, Hiepe T. The treatment of dicrocoeliosis in sheep. Monat Veterinarmed 1993; 48: 657-661.

[14] http://www.emea.europa.eu/pdfs/vet/mrls/3312806en.pdf [consulted $10^{\text {th }}$ December 2007].

[15] Moreno L, Alvarez L, Mottier L, Virkel G, Sanchez Bruni S, Lanusse C. Integrated pharmacological assessment of flubendazole potential for use in sheep: disposition kinetics, liver metabolism and parasite diffusion ability. J Vet Pharmacol Therap 2004b; 27: 299-308.

[16] Nobilis M, Jira T, Lísa M, et al. Achiral and chiral highperformance liquid chromatographic determination of flubendazole and its metabolites in biomatrices using UV photodiode-array and mass spectrometric detection. J Chromatogr A 2007; 1149: 112120.

[17] Prieto JG, Justel A, Del Estal JL, Barrio JP, Alvarez AI. Comparative study on gastric absorption of Albendazole and mebendazole in rats. Comp Biochem Physiol 1991; 100C: 397-400.
[18] Dayan AD. Albendazole, mebendazole and praziquantel. Review of non-clinical toxicity and pharmacokinetics. Acta Tropica 2003; 86: 141-159.

[19] Lamka J, Pe ka R, Kulichová E, Ure ová J, Vondřejc M. Anthelmintic efficacy of orally administered ivermectin against nematodes of mouflon (Ovis musimon). Acta Vet Brno 1996; 65: 225228.

[20] Cringoli G, Rinaldi L, Veneziano V, Capelli G, Scala A. The influence of flotation solution, sample dilution and the choice of McMaster slide area (volume) on the reliability of the McMaster technique in estimating the faecal egg counts of gastrointestinal strongyles and Dicrocoelium dendriticum in sheep. Vet Parasitol 2004; 123: 121-131.

[21] Weaver RJ, Thompson S, Smith G, et al. A comparative study of constitutive and induced alkoxyresorufin O-dealkylation and individual cytochrome $\mathrm{P} 450$ forms in cynomolgus monkey Macaca fascicularis, human, mouse, rat and hamster liver microsomes. Biochem Pharmacol 1994; 47: 763-773.

[22] Reinerinck EMJ, Doorn L, Jansen EHJM, Van Iersel AAJ. Measurement of enzyme activities of cytochrome P-450 isoenzymes by high-performance liquid chromatographic analysis of products. J Chromatogr 1991; 553: 233-241.

[23] Felsted RL, Bachur NR. Mammalian carbonyl reductases. Drug Met Rev 1980; 11: 1-60

[24] Maser E, Oppermann UC. Role of type-1 11beta-hydroxysteroid dehydrogenase in detoxification processes. Eur J Biochem 1997; 249: 365-369.

[25] Palackal NT, Lee SH, Harvey RG, Blair IA, Penning TM. Activation of Polycyclic Aromatic Hydrocarbon trans-dihydrodiol proximate carcinogens by human aldo-keto reductase (AKR1C) enzymes and their functional overexpression in human lung carcinoma (A549) cells. J Biol Chem 2002; 277: 24799-24808.

[26] Ohara H, Miyabe Y, Deyashiki Y, Matsura K, Hara A. Reduction of drug ketones by dihydrodiol dehydrogenases, carbonyl reductase and aldehyde of human liver. Biochem Pharmacol 1995; 50:221227.

[27] Wsól V, Szotáová B, Skálová L, Maser E. Stereochemical aspects of carbonyl reduction of the original anticancer drug oracin by mouse liver microsomes and purified 11-beta-hydroxysteroid dehydrogenase type 1. Chem-Biol Interact 2003; 143: 459-468.

[28] Mizuma T, Mashida M, Hayashi M, Awazu S. Correlation of drug conjugative metabolism rates between in vivo and in vitro: glucuronidation and sulfation of p-nitrophenol as a model compound in rat. J Pharmacobiodyn 1982; 5: 10811- 10817.

[29] Lanusse CE, Prichard RK. Clinical pharmacokinetics and metabolism of benzimidazole anthelmintics in ruminants. Drug Metab Rev 1993b; 25: 235-279.

[30] Galtier P, Alvinerie M. Pharmacological basis for hepatic drug metabolism in sheep. Vet Res 1996; 27: 363-372.

[31] Tekwani BL, Shukla OP, Ghatak S. Altered drug metabolism in parasitic diseases. Parasitol Today 1988; 4: 4-10.

[32] Biro-Sauveur B, Eeckhoutte C, Baeza E, Boulard C, Galtier P. Comparison of hepatic and extrahepatic drug-metabolizing enzyme-activities in rats given single or multiple challenge infections with fasciola-hepatica. Int J Parasitol 1995; 25: 1193-1200.

[33] Calléja C, Bigot K, Eeckhoutte C, Sibille P, Boulard C, Galtier P Comparison of hepatic and renal drug-metabolising enzyme activities in sheep given single or two-fold challenge infections with Fasciola hepatica. Int J Parasitol 2000; 30: 953-958.

[34] Jemli MH, Galtier P, Dorchies P, Benromdhane S, Kilani M. Triclabendazole effect on Fasciola hepatica - induced decrease of biotransformation liver enzymes. Rev Med Vet 1994; 145: 349353.

[35] Habib SL, Sheweita SA, Awad AT, Mashaal NM, Soliman AA, Mostafa MH. Influence of Schistosoma mansoni infection on carcinogen-metabolizing capacities and in vitro aflatoxin B-1 metabolism in human liver. Oncol Rep 1996; 3: 769-773.

[36] Sheweita SA, Mubark J, Doenhofe MJ, et al. Changes in the expression of cytochrome P450 isozymes and related carcinogen metabolizing enzyme activities in Schistosoma mansoni-infected mice. J Helminthol 2002; 76: 71-78.

[37] Awney HA, Ghzlan HE, Sheweita SA, Mostafa MH. Different levels of Schistosoma mansoni infection increased the mutagenicity of benzo(a)pyrene, the activity of aryl hydrocarbon hydroxylase and the formation of hepatic microsomal hydrogen peroxide. Toxicology 2001; 163: 213-218. 
[38] Manhaes-Rocha DA, Conte FP, Fidalgo-Neto AA, De-Oliveira ACAX, Ribeiro-Pinto LE, Paumgartten FJR. Alterations of hepatic microsomal enzymes in the early phase of murine schistosomiasis. Acta Tropica 2005; 95: 58-66.

[39] Sheweita SA, Mangoura SA, El-Shemi AG. Different levels of Schistosoma mansoni infection induce changes in drugmetabolizing enzymes. J Helminthol 1998; 72: 71-77.

[40] García-Llamazares JL, Merino-Pelaez G, Larrode-Pellicer O, Redondo-Cardeša PA, Prieto-Fernández JG, Alvarez-de-Felipe AI. Pharmacokinetics of netobimin and microsomal metabolism of albendazole in infected gerbils with Echinococcus granulosus. Parasitol Res 2001; 87: 107-111.
[41] Galtier P, Alvinerie M, Plusquellec Y, Tufenkji AE, Houin G. Decrease in albendazole sulfonation during experimental fascioliasis in sheep. Xenobiotica 1991; 21: 917-924.

[42] Delatour P, Garnier F, Benoit E, Caude I. Chiral behaviour of the metabolite albendazole sulphoxide in sheep, goats and cattle. Res Vet Sci 1991; 50: 134-138.

[43] Velík J, Baliharová V, Skálová L, Szotáková B, Wsól V, Lamka J. Liver microsomal biotransformation of albendazole in deer, cattle, sheep and pig and some related wild breeds. J Vet Pharmacol Therap 2005; 28: 377-384

[44] Hiendleder S, Kaupe B, Wassmuth R, Janke A. Molecular analysis of wild and domestic sheep questions current nomenclature and provides evidence for domestication from two different subspecies. Proc. Roy. Soc. London B Biol Sci 2002; 269: 893-904. 